\title{
THE CONCEPTS AND DESIGN OF ROC DEFENSE REORGANIZATION
}

\author{
Ching-Pu CHEN
}

\begin{abstract}
The defense organization of the Republic of China (ROC) Taiwan has undergone a dramatic transformation in recent years since the acceptance of the National Defense Act and the Ministry of National Defense Organizational Act in the year 2000. The new defense organization is believed to enhance strategic planning, resource allocation, joint operation, and civilian control. This article describes the concepts and structure design behind the two Acts mentioned above. It also presents the defense planning systems for force building.
\end{abstract}

Keywords: Defense reorganization, defense management, organizational design, strategic planning, resource allocation, joint operation.

The acceptance of the National Defense Act and the Ministry of National Defense Organizational Act (hereafter referred as "the Two Defense Acts") in 2000 have marked a milestone in the Republic of China's (ROC) military reform. As the Revolution of Military Affairs (RMA) emphasizes the joint synergy of operational concept, organizational structure and technology, the Two Defense Acts bring in new organizational concepts and structures that lay the foundation for ROC's military establishment in the $21^{\text {st }}$ century.

Conceptually, an organizational design involves two parts: hardware and software. The hardware sets the framework, infrastructure and backbone of an organization's machine and the software makes the machine run. The hardware side of the organizational design includes the organizational structure, distribution of authority and responsibility, control mechanisms, etc.; while the software involves the operational system, process, procedure, culture, people and leadership, etc.

In addition, any organizational design has to reflect the strategy and concept for its competitiveness. This article will describe the defense structure before and after the Two Defense Acts (referred to as the Old and the New defense structure, respectively), the external environment motivation, and the design concepts and principles 


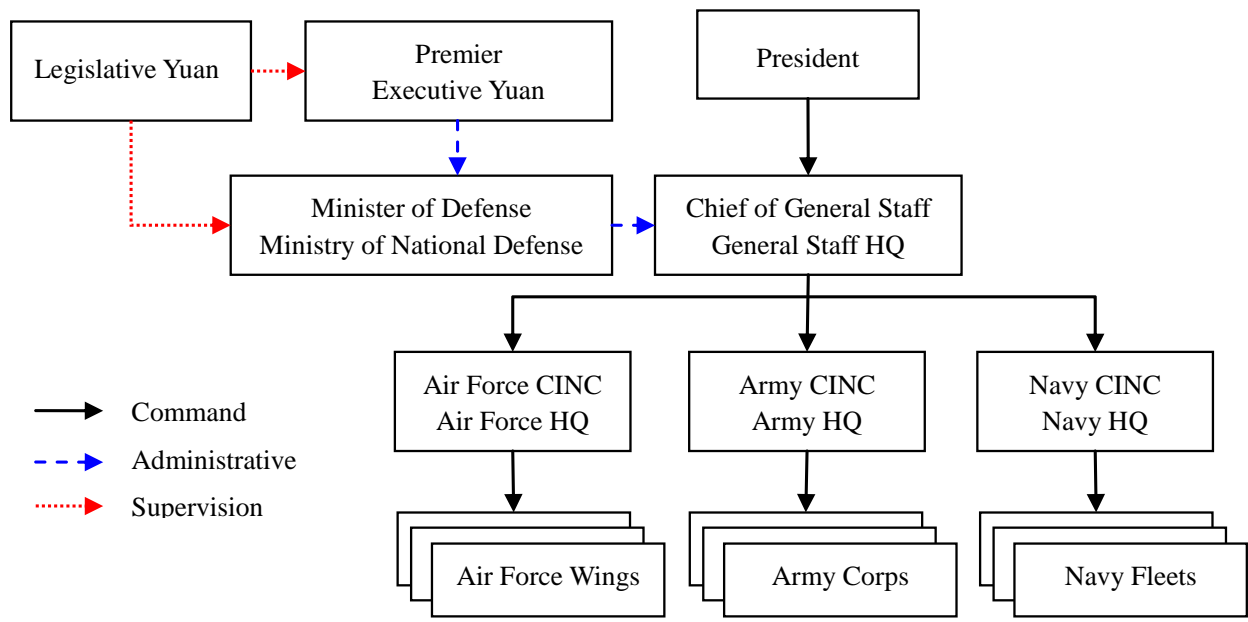

Figure 1: The Defense Structure before the Two Defense Acts.

behind the New defense structure. It will also elaborate on the new defense structure (hardware) and the process (software) of defense building.

\section{The Old Defense Organization and Problems}

The ROC's defense structure has remained largely the same with some minor changes since the national government moved to Taiwan from Mainland China in 1949. So, its designed structure is tailored not only for large territory (about 268 times larger than Taiwan), but also for the recovery of Mainland China. After more than 50 years, the national objectives have changed, the international environment is different, and the military operation and warfare are undergoing a dramatic shift in form. The ROC's defense organization has become an outdated awkward system.

\section{Old Systems}

In the Old defense system, the President had the sole control of the military command through the Chief of the General Staff (CGS) and the General Staff Headquarters (GS HQ), which was responsible for personnel, strategy, operation control and resource allocation planning, in addition to technology R\&D, weapon procurement, logistics, political warfare, military policy, and reserve forces. While the Minister of Defense (MD) and the Ministry of National Defense (MND) HQs only take care of general defense policies, which also need the support from the CGS, yet they have to face the Legislative Yuan's (LY, the Congress) interpellation to advocate and defend defense policy and budget. The armed forces of the respective services are under the com- 
mand of the respective service HQs. So, the Chief of the General Staff has to conduct joint operations through the services' HQs (see Figure 1).

\section{Problems and Shortcomings}

The Old defense structure had the following shortcomings:

- The Chief of the General Staff had the authority over almost all military affairs; yet, he was only responsible to the President. They both had very little supervision from the LY. So, the people or the LY representing the people had very little control or supervision over defense policy, military affairs, and budget allocation.

- Although the Minister of Defense had the responsibility to oversee defense affairs and was responsible to the LY, he did not have the authority over the majority of military affairs.

- The decision mechanism for defense organization had insufficient functions for effective decision-making, planning, evaluation, and audit. It was mainly in the hands of military officers without civilian involvement.

- With the homogeneity of personnel (almost all from the same military school system) and without diversity, it is likely to develop a narrow view of the future with the possibility of "groupthink."

- The stovepipe command organization makes the defense establishment inefficient, with lack of responsiveness and flexibility.

- The Chief of the General Staff conducted joint operations through strong and independent service HQs that makes it difficult to integrate the operation and to respond to crises.

\section{Future Environment and Challenges}

Since the recovery of Mainland China, the objective and strategy of ROC's national security have changed to resolute defense and effective deterrence of potential attacks on Taiwan and its surrounding islands under ROC's sovereign control. Also, there have been dramatic changes that occurred in the environment, such as the following:

- Geostrategic Difference. Since the end of the Cold War, the world has changed into one superpower with many regional powerful nations. The traditional ideology, alliance and nations ease their influences to economic development. The roles of military to national security also vary. With the adjustment of many nations' defense and readiness, the regional security frameworks are also taking different forms.

- Cross Strait Situation. With the rise of the People's Republic of China (PRC) in the Asia region, its economic growth and defense modernization 
are taking up a rapid pace. So is its comprehensive national power. In the meantime, ROC's defense budget took a declining pace. It declined from $22.67 \%$ of government budget (3.57\% of GNP) in 1996 to $16.48 \%$ ( $2.77 \%$ of GNP) in 2001. Even the Cross Strait relation appeared to be warming up with more interaction, the basic tensions still existed in national interests and military. This posed a great challenge to build an appropriate defense force and its management structure.

- Information Age. "Knowledge is power." The warfare has changed from attrition to paralyzation. With the arrival of the information age and the new capabilities brought about by information technologies, many countries have initiated their respective RMA trying to blend together operational concepts, organizational structure and technology to meet the future defense demands. With the huge difference in size, this will be an important factor for Cross Strait military balance.

- Changing Warfare. The future warfare will be characterized by "2Q1S." Crises or wars might erupt "Quickly" and also end "Quickly", but it will take a long time for "Slow" recovery. It is especially critical for the ROC because of its close proximity to PRC. Therefore, ROC must build a quick, flexible, adaptive, and robust defense force and mechanism that are able to sustain the first strike and conduct an endurable operation and command structure.

With these insights, there is a pressing demand and motivation for the ROC to design a more efficient professional military organization with effective command and control system for both peace and war time.

\section{Design Concepts and Principles}

The new defense reorganization has the following goals:

- To establish a unified defense system under civilian control and LY supervision;

- To build a professional and efficient military structure;

- To improve defense decision-making functions;

- To enhance the joint operation mechanism for rapid response and adaptivity;

- To modernize the armament acquisition system;

- $\quad$ To advocate all-out defense. ${ }^{1}$

To achieve these goals, the principles for the new defense design are as follows.

\section{Democratic Defense System}

Military establishment is an authorized fighting force with huge destructive power 
entitled by the people to protect their lives and welfare. History is filled with cases where warlords used military forces against their own people and brought devastation. Hence, in a democratic country, the military power needs to be controlled by authorized civilians, usually the elected President and/or the Minister of Defense.

A country's power structure can be divided into three bodies: national policy making, policy execution and policy supervision. Each body has its role and responsibility. This is not only a separation of power, but also a check and balance design with a division of labor for national power utilization. Consequently, the new defense organization should reflect the above mentioned principles.

\section{Competitiveness and Adaptiveness}

Even though stability and control of military forces are necessary for the democratic countries, the military establishment should also focus on its main function that is a quick and effective response to national crises and wars. To balance these requirements poses a great challenge. Since Mainland China is only 134 miles away from Taiwan Island, the ROC must maintain a competitive and adaptive force structure and organization in order to meet the challenges from the PRC and the changing environment. Therefore, a responsive unified command, as well as flatter organization and slimmer process are necessary requirements for quicker and flexible response. In addition, each component should have a clear role and mission to provide value added functions and to avoid the shortcomings caused by a stovepipe redundant organization.

\section{Accountability}

Those who have the authority should also bear the respective responsibilities. Each organization must align its authority and responsibility according to its role, function and mission. With this assumption, the defense hierarchical structure can be more easily managed and linked by objectives. In a democratic society, the armed forces must be under civilian control with proper supervision from the LY. Therefore, the Minister of Defense must have the authority and responsibility over military administration, command and armament, and meanwhile respond to the President, the Prime Minister, and the LY.

\section{Professional Division of Labor}

Professionalism is an important element of modern military operations. Any organization with a high level of profession or skill often relies on specialized division of labor. Military affairs involve many professions. The new defense organization should be grouped by participants' professions, so that professionals can manifest their skills and develop their professional careers. The new defense organization has to cultivate professional personnel and its development, and create an environment 


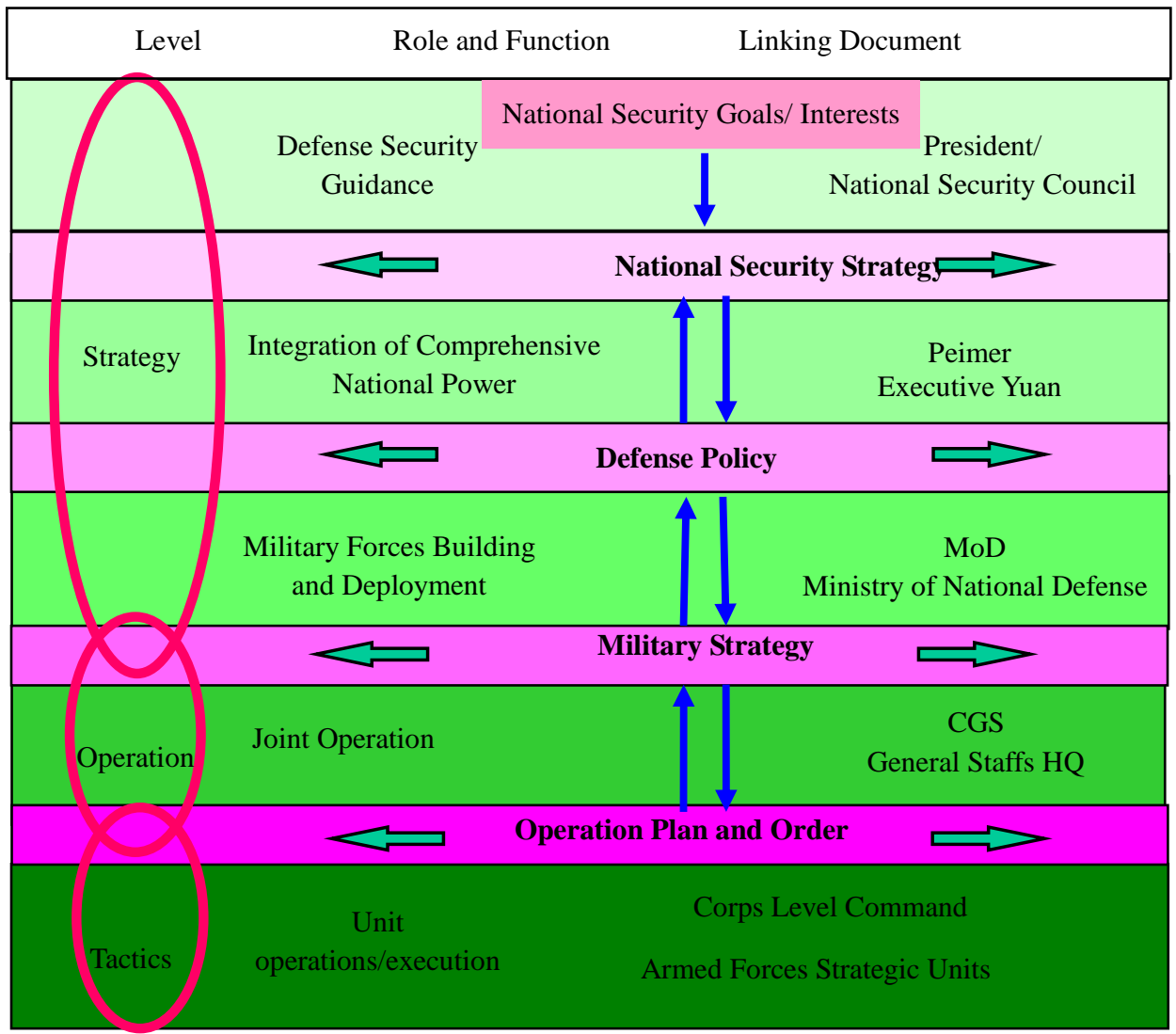

Figure 2: Defense Organization Hierarchy.

for professional integrity. This is the structure (hardware) side of the organizational design.

\section{Coordination and Integration}

The challenge for the professional-division-of-labor structure lies in its coordination and integration. Therefore, an integrated process and mechanism must be installed to ensure coordinated and aligned actions among these functions and to make it an effective organization. This is the process (software) side of the organizational design.

\section{Main Features of the New Defense Organization Structure ${ }^{2}$}

\section{Defense Hierarchy}

There is a constitutional ambiguity debate on whether ROC is a presidential or pre- 
mier system. The ROC constitution states that the Executive Yuan (EY) headed by the Premier is the highest executive body. However, the Premier is appointed by the President who is elected by the people. At this point, there is a common understanding that the President is in charge of the defense, diplomatic and Cross-Strait matters, while the EY takes care of the domestic administrative government. Therefore, in the defense arena, the President with the advice of the National Security Council sets the national security strategy and guidance. The Premier will compile the defense policies that can align and coordinate governmental departments to support national defense. MD/MND then in turn formulates military strategies for achieving the national military objectives. Afterwards, CGS will take care of all operational plans for foreseeable crises and military operations, and the armed forces will execute operations under the CGS's command (as shown in Figure 2).

\section{Division of Labor: Military Administration, Command, and Armament}

The goal of the military establishment is to build armed forces that can perform their role and mission efficiently. There are two major tasks of defense management: administrative management and operational command, which correspond to the concept of separation into force provider and force user. The new defense structure is divided into three pillars: Military Administration, Military Command, and Military Armament (as illustrated in Figure 3). The functions of the Military Administration are to direct defense building by setting objectives, strategies, and policies, and to obtain

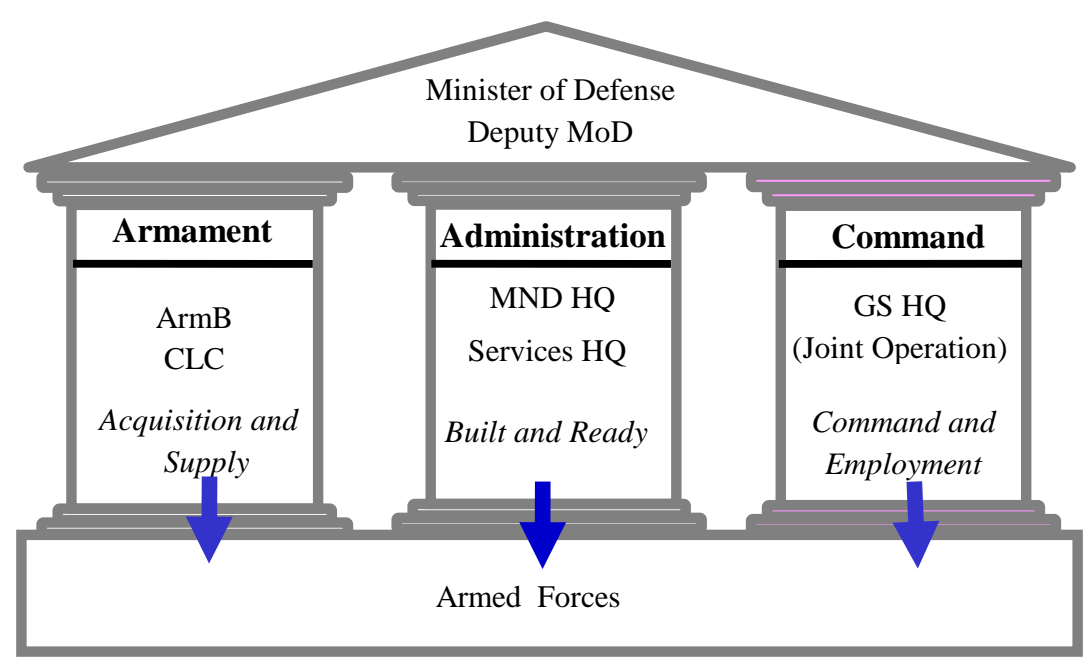

Figure 3: The Three Pillars of the New Defense Structure. 
and manage the necessary defense resources. The Military Armament acquires and deploys military weapons and materiel to be used by the armed forces, and distributes supplies through the integrated logistics system. Military Administration and Armament sections are the force providers with focus on administrative management, while the Military Command section is the force user and the joint operation command, which follows the guidance from MND to plan, prepare and conduct joint military operations on the forces provided. This separation clarifies the roles and responsibilities of these three sections, so that each of them can focus on their respective responsibilities and improve the overall effectiveness.

More specifically, the Military Administration has the following functions:

- Setting and formulating defense goals, objectives, strategies, and policies;

- Overall resources planning, acquisition, management, and allocation with priority;

- Human resource recruitment and development (with education system);

- Military system performance evaluation and supervision;

- Other administrative functions.

The Military Armament is in charge of research, development and acquisition of military weapons and equipment, which supports the armed forces with modern weaponry. It consists of the Armaments Bureau (ArmB), the Combined Logistic Command (CLC) and the Chung-Shan Institute of Science and Technology (CSIST). ArmB manages the armament acquisition process, and CSIST is its R\&D branch. CLC provides the integrated logistics support to the troops.

Service HQs is now part of military administration or force providers. They develop doctrine, equip troops, and provide basic and combined training to personnel. So the service HQs play the role of transforming people and weapons received into different types of strategic modules as professional fighting units.

The Military Command must demonstrate its effectiveness and efficiency of joint operations. According to the new defense design, the President directs and delegates the authority of command to the MoD who can give orders to CGS for conducting military operations. Hence, CGS shall possess the capabilities to plan, train, execute and evaluate joint operations, and to assess and request military requirements that MND should provide for its joint operations. CGS with staff support from the GS HQs can command the armed forces either through the corps level commander or directly.

This design reflects the principles of professional division of labor, unified command, streamline management, centralized planning, and decentralized execution. 


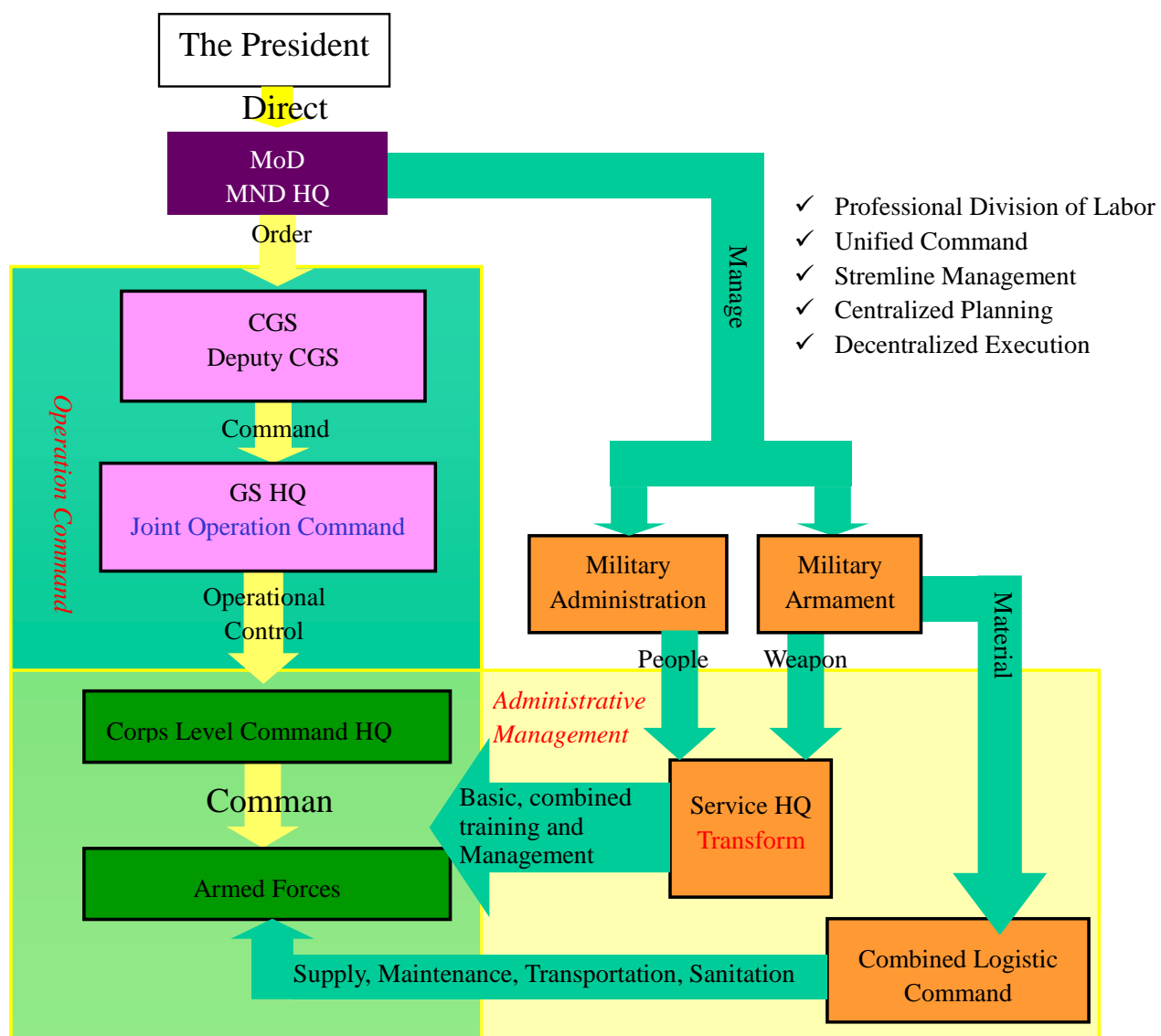

Figure 4: The Conceptual Framework for Administration Management and Operation Command.

\section{Civilian Control}

Figure 4 illustrates that the MoD not only commands the armed forces through the CGS, but also manages the military administration and armament to support military operations. So the civilian MoD will have the control and management responsibility over all military affairs. 


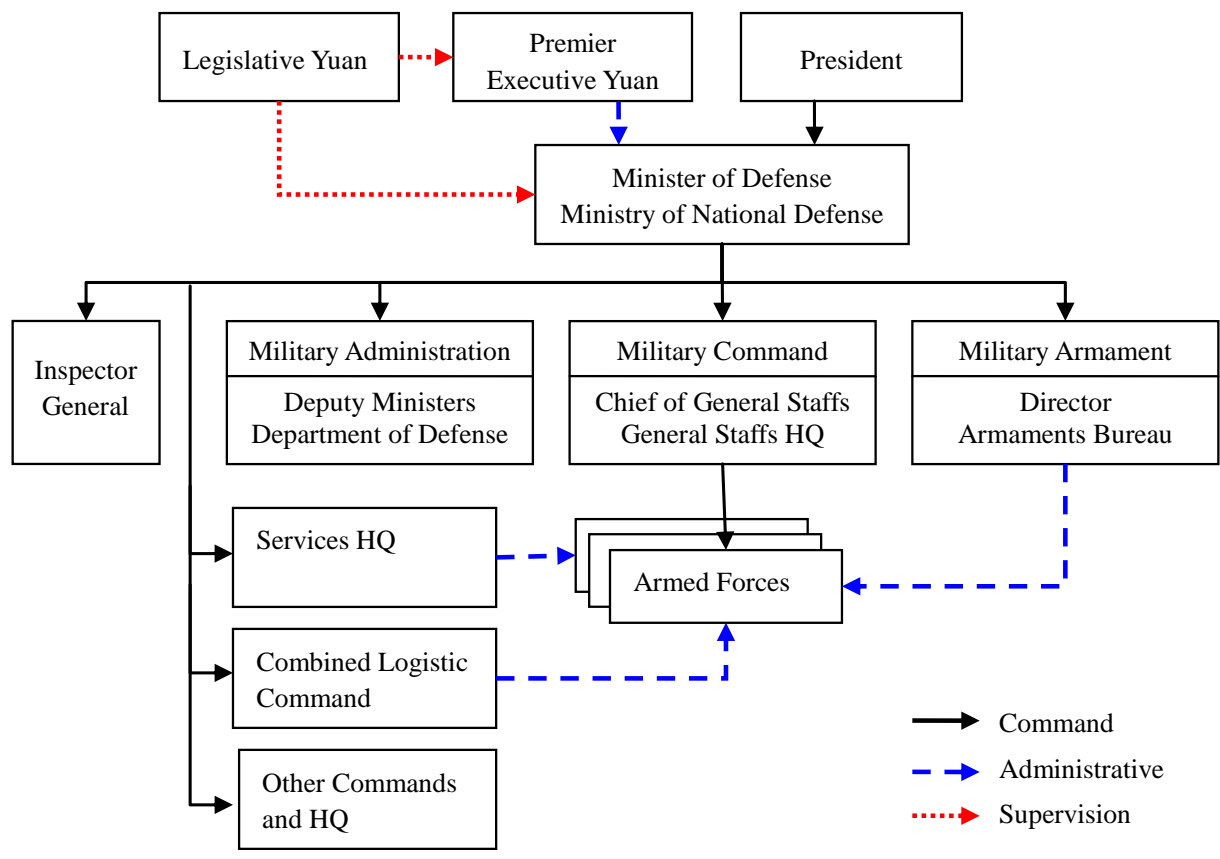

Figure 5: New Defense Structure after the Two Defense Acts.

Since the new defense design shifts major powers from the CGS to the civilian Minister of Defense who is a cabinet member of the EY and must answer to the LY, the new MND can be better governed and supervised by the EY and LY (see Figure 5).

Even though the civilian leaders have the command of armed forces, they have to rely on professional military commanders to plan and conduct military operations. Main responsibilities of the civilian leaders are to set the goal and guidance for military operations and to provide the necessary resources, and not to interfere with professional military operations.

\section{Strategic Planning, Resource Allocation, and Management}

Main responsibility of MoD is to set the direction of force building, to formulate military strategies, to obtain and allocate defense resources, and to manage the large and complex defense establishment. In order to manage the complex military affairs and its responsibilities in strategic planning and resource allocation decisions as well as those related to execution supervision, the civilian MoD should have the support of capable staff organization. Therefore, the Two Defense Acts establish several new 
departments for the above-mentioned functions: Department of Strategic Planning (DSP), Integrated Assessment Office (ISO), and Department of Resources (DOR).

The Department of Strategic Planning manages and develops national military strategies that comply with and support national principles of all-out defense and the national security strategy.

The Integrated Assessment Office establishes the required capabilities in order to perform unbiased and trustworthy assessment and analysis of defense programs and military readiness. So, ISO can provide recommendations concerning the decision of defense resource allocation and other important defense affairs effectively.

The Department of Resources is reorganized to encompass acquisition and integration of national defense material and financial resources, as well as the policy planning and supervision of national defense technology and industry development.

\section{Joint Operation: Slimmer and Flatter Chain of Command}

To make the joint operation more effective and efficient, the new defense design has removed most military administrative and armament responsibilities from the GS HQs and assigned them to the top military joint operation command HQs that concentrates on planning, preparation, and execution of joint operations. In order to have a more integrated operation and a direct control over the armed forces, the services HQs have been removed from the chain of command. With this change, the chain of command becomes slimmer and flatter, hence more responsive and flexible to different demands and a changing environment.

\section{The Defense Building System and Process}

With the New defense structure and framework in place, it is the process and people that actually make the system operate. This section will portray two important defense management processes: the forces building cycle and the defense planning system.

\section{The Forces Building Cycle}

To build a capable defense force, the highest level decision makers that include the President and the MoD's defense guidance on national security interests, goals, constraints, have to be considered first. The strategic planners in the DSP start a process of formulation of a national military strategy and transform it into defense planning guidance. The executioners, such as the service HQs and GS HQs, then submit program requirements deemed necessary to fulfill their roles and functions. The IAO first evaluates these programs based on cost/benefit analysis and support for military strategies from an integrated defense point of view, and then presents its assessment and recommendations to the high-level decision makers to resolve major issues and 


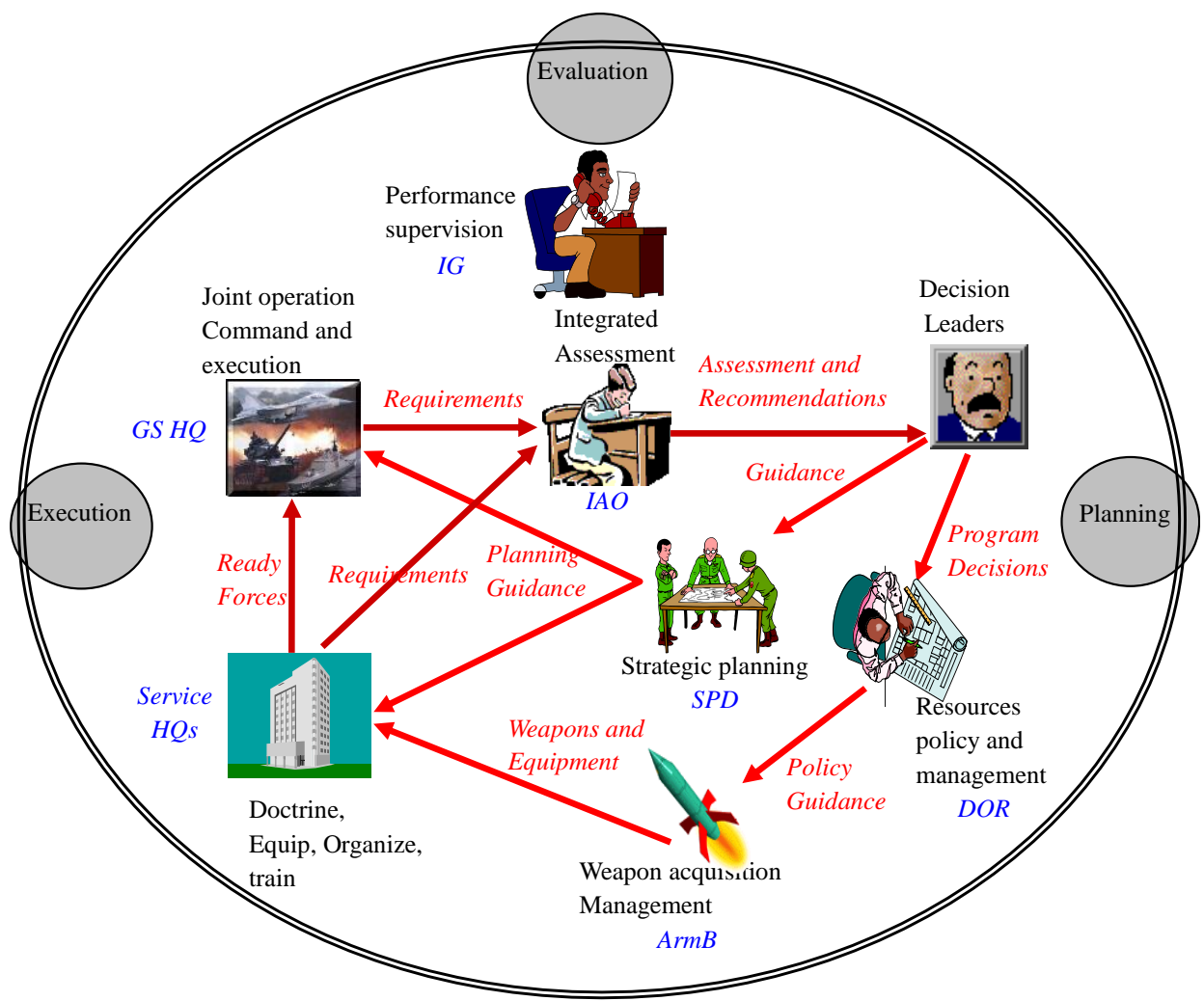

Figure 6: Defense Building Process.

make the final program decisions. With these decisions and guidance made, the resource planners within the DOR consider the future resource availability and constraints, and turn them into human, materiel/weapon, technology and financial policies. The ArmB then plans the strategies and approaches to acquire those weapons and equipment. Each service HQs develops its respective doctrine for organized, trained and sustained fighting force module from the personnel, weapons, equipment and materiel they receive. The ready forces are then transferred to the command of the CGS. This becomes a continuous cycle for building and strengthening of defense forces. Next, there is Inspector General (IG) that will supervise the process and the performance of the major defense components. The process of building defense forces is illustrated in Figure 6. 


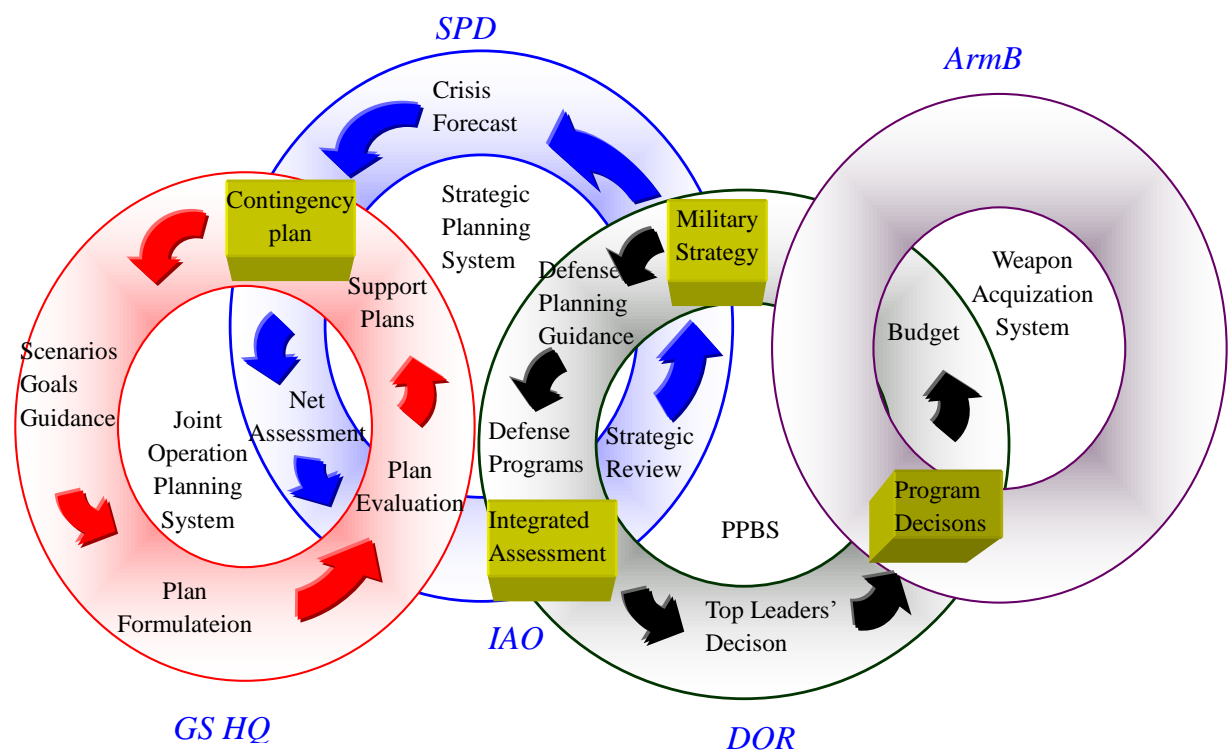

Figure 7: Systems of Defense Planning.

\section{The Defense Planning System}

There are four major cyclic functions in defense planning: strategic planning, resource allocation, armament acquisition, and joint operation.

The defense apparatus should conduct net assessment of the future environment to formulate strategic goals and plans and to predict potential crises. The next cycle is to allocate resources (budget, materials, and personnel) to support the defense strategy. With the defense and resource policies, the armament apparatus plans the best ways to acquire necessary weapons and materials through $\mathrm{R} \& \mathrm{D}$ and manufacturing or through foreign procurement or joint venture. Considering potential outburst of crises or wars, the joint commanders should develop operational plans for different scenarios under the guidance of contingency plans from the MoD. In the past, strategic planning and resource allocation decisions used to be responsibility of the Deputy Chief of Staffs for Planning (J5) of the GS HQs. Because these two important functions are performed within one unit, it is difficult to conduct independent and unbiased planning and assessment. Thus, the new defense design separates these two functions to be performed by SPD and IAO, respectively.

These four functions have semi-independent processes, which need to be coordinated and synchronized. To link these processes, four important documents or decisions are 
needed. The national military strategy from the SPD is one important document that guides resource allocation assessment and decision. The integrated assessments of required programs from the IAO serve as references for top decision makers to make the final defense program decisions. The decisions and policies made by the top leaders then serve as goals to acquire necessary weapons and materials by the ArmB. And the Contingency Plan from the MND provides the scenarios, goals, guidelines and resources available for the CGS to plan for joint operations. The strategic planning, resource allocation, policy making, weapon acquisition and joint operation planning systems are managed by the SPD, DOR, ArmB and GS HQs, respectively. The systems are depicted as shown in Figure 7.

\section{Conclusion}

The Two New Defense Acts marked a milestone in ROC's RMA. They have changed the fundamental organizational structure and power distribution to make ROC military more adaptive to modern warfare and democratic requirements. With the professional division of labor, clarification of role and mission, and proper distribution of power and responsibilities, the new defense structure can provide a better foundation for strategic planning, resource allocation, and joint operation. However, it is the people who make the system work and excel. This requires a lot of paradigm shifts, reeducation of people and total committed efforts for continuous process improvement to make the new defense organization and system perform as desired.

\section{Notes:}

${ }^{1}$ National defense is responsibility of all citizens. MND can not carry the responsibility for national defense without the support and assistance of all citizens. Therefore, ROC defense should develop a system that incorporates its citizens not just physically, but also in mind through reserve and educational systems.

2 The following figure or description might not reflect the complete system of the new defense structure, but only the aspects related to strategic planning, resource allocation, and joint operation.

CHING-PU CHEN was awarded the First Jackson Hope Medal from the Virginia Military Institute with a BS in EE \& Math in 1985, and MS and Ph.D. from Harvard University in Engineering Sciences and Decision Sciences. He was the director of the Graduate School of Defense Decision Sciences, National Defense University, Taiwan, R.O.C. He was a visiting fellow at CISAC, Stanford University, a director of the Chinese Decision Sciences Association, the Taiwan Operation Research Association, and a project team member of ROC defense reorganization. Ching-Pu retired from the ROC Army as a colonel, and now is an associate professor/director at the Yuan Ze University. His research interests include decision science, crisis management, organizational reengineering and professional ethics. 